\title{
INDIVIDUAL DEVELOPMENT IN A BIO-CULTURAL PERSPECTIVE
}

Fausto Massimini and Antonella Delle Fave

Dipartimento di Scienze Precliniche "L.I.T.A. Vialba", Facoltà di Medicina e Chirurgia, Università degli Studi di Milano, Italy.

Published in: American Psychologist, 55, 24-33 (2000). 
"Watch well over your seed-things and children!

Speak wisely to these our new children!

Henceforth they shall be your first speakers,

And the peace-making shield of your people."

Zuni Creation Myth

The primary role of psychology, as stated by the editors of this special issue should be the formalization of models of healthy behavior, which could be fruitfully applied to the study of human development and used in intervention programs in the fields of psychic maladjustment and psychopathology. We share this opinion, as emphasized in previous works (Massimini, Csikszentmihalyi, \& Carli, 1987). In this article we want to analyze the basic features of humans that led to the development of culture and consciousness, the two basic pillars of our history. We adopt a developmental perspective, considering human psychological processes as an emergent adaptive trait that brought about deep changes in both the ecosystem and the evolution of our species. We propose a model of healthy behavior that can shed new light on the potentially constructive role of individuals in their bio-cultural context.

As our theoretical guidelines we refer to concepts coming from two main fields concerned with the study of living systems. The first is the natural selection paradigm, the formalization of which had an enormous impact on the development of biological and social sciences in the 20th century. Specifically, the key concept of phenotypic variation as the basic substrate for biological selection and evolution has been fruitfully applied to the study of social and cultural systems. The second field we refer to analyzes living systems as open and selforganizing units, intrinsically oriented toward complexity and neg-entropy (i.e. order and integration) thanks to the continuous exchange of information with the environment. These concepts have been used in biology, as well as in the study of social systems (Khalil \& Boulding, 1996; Maturana, 1975; Monod, 1970; Prigogine \& Stengers, 1984; Varela, Thompson, \& Rosch, 1991).

Biology, culture, and individuals: three interacting systems

Biology and human evolution. Biological inheritance obviously influences human behavior. This influence has been stressed and investigated by a growing number of studies conducted within the framework of sociobiology and evolutionary psychology. In this perspective, the main part of human individual and social behavior has evolved in order to ensure survival and reproduction in our ancestors' Environment of Evolutionary Adaptedness (EEA; Symons, 1990). The differential replication and transmission of behavioral sequences is related to the enhancement of inclusive fitness (Alexander, 1987; Barkow, Cosmides, \& Tooby, 1992; Buss, 1989; Trivers, 1972; Wilson, 1976). Social learning, altruism and the development of moral norms are also explained in this perspective (Flinn, 1997; Grinde, 1996; O’Neill \& Petrinovich, 1998). Psychopathology is analyzed in terms of maladaptive traits and/or inertia of previously adaptive behavioral patterns, or both (Stevens \& Price, 1996). Geographical variations in human behavior and social organization are explained as strategies that have evolved to cope with the demands of radically different natural environments (Foley, 1992; Kaplan \& Hill, 1992).

Of course, we do not deny the fundamental influence of the biological inheritance system 
in shaping human behavior. In our opinion, however, this perspective is reductionist at two levels. First, the role of culture's development and cultural learning in human history is not adequately evaluated. As a great number of interdisciplinary studies show, far from being simply an epi-phenomenon of biological traits, culture does have a dramatic impact on human behavior. As a consequence, with the passage of time individuals have had to cope with environmental demands that have become very different from those related to the ancestral EEA.

Second, a strictly evolutionary perspective does not leave much hope for the actualization of cultural values such as peaceful and cooperative relations, equality, and tolerance. Every unit of human behavior is enacted under the ultimate pressure of inclusive fitness. Social interaction is basically manipulative; deception is common; strong social hierarchy and sexual stratification are the rule. In this picture, several widespread and accepted behaviors stemming from culture would have no reasons to exist. International child adoption would not be promoted. Disabled people would have few chances to survive and to reproduce. Males' mating strategy would be aimed at maximizing inclusive fitness, thus supporting polygamy in all human communities.

We think that a biologically grounded model leaves no room for the system of values, focused on democracy and individual rights that has been laboriously developed in several cultures, at least during the last three centuries. These values are the inspiring guidelines of many societies. If we disregard them as epi-phenomenal and subject to biological fitness, how can we build a psychological model based on human development as a growth toward individual complexity and cultural integration, shaping human beings as full-fledged members of mankind?

Culture and human behavior. The adaptation strategy of our species is based on social learning and on the production and use of artifacts, material or symbolic. This strategy was supported by specific biological features, namely the upright position, the opposing thumb and the impressive growth of brain structures both in mass and complexity. In particular, humans evolved specific psychic processes, defined by Crook (1980) as awareness of external world (subjective self-awareness) and awareness of one's own internal state (objective self-awareness). From a different perspective, Edelman $(1989$, 1992) distinguished between primary consciousness (an adaptive trait shared by various species) and higher-order consciousness, defined as the uniquely human ability to remember, make plans, and set goals on the basis of memorization and selective retrieval of information acquired through experience.

Humans started to manipulate the environment, to build artifacts, and to create social norms and roles; this set of products, which can be labeled as culture, promoted our species' settlement in various ecological niches. The symbolic representations of the external world and of individuals themselves were formalized by means of descriptions and behavioral rules stored in the individual central nervous system (intrasomatic level) and in material tools, books, and artistic and religious artifacts (extrasomatic level). The horizontal and vertical transmission of cultural information, by means of verbal language, social learning and artifacts contributed to the development of cultural systems (Cloak, 1975). Survival became more and more dependent on the acquisition of cultural information, and life became an unceasing learning process (Tomasello, Kruger, \& Ratner, 1993).

The influence of culture on human behavior is a main issue in cross-cultural psychology. From cognition to social behavior and human development, behavioral differences among individuals can often be traced back to different cultural contexts (see Segall, Lonner, \& Berry, 1998 for a synthetic overview of the state of the art). The study of culture-specific models of human behavior has been recently promoted by cultural psychology (Stigler, Shweder, \& Herdt, 
1990) and indigenous psychologies (Kim \& Berry, 1993).

Several efforts have been made to formulate suitable definitions and models for culture. Dawkins (1976) used the term meme to define the basic cultural unit, subjected to differential replication according to its biological fitness. According to bio-cultural theories (Boyd \& Richerson, 1985; Durham, 1982, 1991; Richerson \& Boyd, 1978; Ruyle, 1973) human behavior is influenced by a dual inheritance system based on genes and memes. In contrast with Dawkins' perspective, culture is described as an evolving system that progressively gains autonomy from biological pressures. Memes are submitted to differential replication, under biological or cultural pressures, or both: this process leads to selection and evolution of cultures.

It is impossible here to go into the detailed mechanisms of cultural selection and evolution and the various interaction patterns between genes and memes. Following Durham (1991), we briefly point out two main issues. First, culture evolves as an autonomous system thanks to the creation of secondary values, stemming not from individual ontogeny (like the primary ones), but from social history. Memes' differential replication can consequently depend upon criteria that are 'purely cultural', autonomous from the biological fitness of the group. Moreover, the factors influencing the selection of genes and memes are different. The former is the differential survival and reproduction of the carriers (that which Durham calls selection by consequences); the latter is the assumption on the cultural meaning and usefulness of memes (selection according to consequences), which can precede the actual evaluation of memes' transmission outcomes. Second, memes' differential reproduction can interact with biological fitness in three different ways: enhancing it, decreasing it, or being neutral in respect to it.

As concerns the first issue, meme selection and organization in cultural systems has been analyzed by studying constitutions, as sets of cultural information that regulate individual and group behavior (Calegari \& Massimini, 1978; Massimini \& Calegari, 1979). Constitutions comprise the basic social values, which can be defined as assumptions on what is desirable for the individual and for the group in a specific culture (Rokeach, 1974; Calegari \& Massimini, 1976). The analysis detected 11 recurring groups of norms, which were treated as units of a cultural network. Each unit deals with a major problem that society has to solve in order to survive and reproduce in time. The units can be grouped into four categories, according to the issues they deal with: 1.bio-cultural reproduction (work, property, income), 2.cultural reproduction (education, information exchange, participation, decision making), 3. prescription (legal system, status), 4. evaluation and justification (individual values, social values). Within the cultural network, the units are connected by mutual influences. Each culture develops specific solutions to the problems represented in the units according to its meme selection history. Cultural networks have also been detected in orally transmitted instruction sets (Massimini, 1982). From another perspective, Pocklington \& Best (1997) studied selection and replicative success of memes in a corpus of texts posted to a Internet-based news system, in which they looked for sets of repeatedly co-occurring words, their variation and persistence. Further studies are indeed needed in the field.

Memes are differentially replicated and transmitted by means of imitative behavior, oral communication, and artifacts' reproduction, through choice or imposition. New memes can be introduced in a cultural system by means of inventions or acquisition from other social groups.

The same unit of behavior can be regulated by several meme variants. These variants compete for differential replication and transmission at two levels: within culture and between cultures. Within a community, the introduction of a new meme or the competition among variants of the same meme can explain the historically frequent phenomenon of village fission and the subsequent emergence of new habits, languages, and cultural systems. Debates in the 
sciences and humanities can be translated in terms of meme competition. Political parties are expressions of differential meme replication. Changes in the content or number of articles in a constitution are manifestations of meme selection.

At the intercultural level, societies may fruitfully exchange and borrow memes. We have to admit, though, that the most frequent event in human history has been competition and imposition of memes from one culture to another one. Only one example, however systematically recurring, will be reported here: Wars, mostly grounded in cultural beliefs and values, are the very basic leit-motiv of the interaction among societies.

Given the cultural relativity of memes' fitness, which is based on assumptions about their value within a specific society, cultural evolution is a process of change in neutral terms: change per se does not necessarily mean improvement, but fitness enhancement. Given the possibility of memes' spreading through imposition, some cultures can dominate others because of the cultural fitness of their memes (i.e., ability to survive and reproduce in respect with other memes' variants, and not because of the absolute desirability of the values they convey). For example, during the second millennium BC patriarchal warfare societies defeated and suppressed more egalitarian and peaceful cultures settled in the Middle East, South Asia and the Mediterranean area. These cultures were based on agricultural and trading economy, gender equality and a religious system centered on Mother Goddess and fertility rituals (Eisler, 1987; Gimbutas, 1991). They disappeared not because of the low desirability of their value system but because of their lack of artifacts and know-how related to war. In the last four centuries, cultural extinction has been repeatedly caused by means of violent colonization, wild modernization, and supremacy of technological power. This form of meme selection through imposition inhibits the differentiation process, which is a basic feature of living systems, be they species or cultures.

As concerns the interactions between memes and genes, culture often contributes to enhance the biological fitness of the group; food and housing habits, parenting practices and healing systems are generally aimed to enable and improve human biological survival and reproduction. However, human history is interspersed with cases of competition between biological and cultural fitness (Boyd \& Richerson, 1985; Massimini, Inghilleri, \& Delle Fave, 1996). Intraspecific violence and biological suppression due to religious, political and economic reasons; gulags and concentration camps; religious celibacy; female infanticide; family size reduction; and child abuse are only some examples of this phenomenon. As concerns memes' interaction with the ecosystem, the changes of a culture in time are often adaptive responses to ecological modifications. However, in most parts of the world today, the artificial environment has gradually overcome and often substituted for the natural one, sometimes with devastating effects on the ecological niche and on the survival of a great number of living species (Brown, Flavin, \& French, 1998).

Subjective experience and psychological selection. It is very difficult to independently evaluate the influence of biological, environmental and cultural factors on the phenotypic behavior (Altman and Chemers, 1980). Studies deriving some concepts from the living system theory (Miller, 1970) called for a circular causal relationship between individual behavior, biology, and culture (Richerson \& Boyd, 1978; Massimini, 1982).

Moreover, concerning culture, memes first stem from individuals, who are the actual inventors of ideas, artifacts, and value systems (Durham, 1991). Each peace of cultural information was originally an individual solution to a specific problem and this has enormous implications for the potential role of each human being in the construction of society, as other scholars have often clearly stated (see Jung, 1932/1972) and as we discuss in the following 
pages.

Being both reproducer and transmitter of bio-cultural information units, each human being actively influences the survival and replication of biological and cultural pools. This influence is again based on a selective process, which has been defined as psychological selection of bio-cultural information (Csikszentmihalyi \& Massimini, 1985). The process is shaped by two specific human features: the subjective-objective awareness and the limited amount of attention resources (Csikszentmihalyi, 1978). Individuals cannot pay attention to all occurring environmental stimuli at the same time. Thus, they have to select a subset of this information - daily activities, situations, and social contexts - to be involved in. As a wide range of studies have pointed out, the main factor directing psychological selection is the quality of experience. Individuals preferentially invest their attention in environmental opportunities associated with positive and rewarding states of consciousness, in particular with optimal experience, or flow (Csikszentmihalyi, 1975, 1978; Csikszentmihalyi \& Csikszentmihalyi, 1988).

Optimal experience is characterized by the perception of high environmental challenges, matched with adequate personal skills. Individuals report high levels of affect, concentration, and involvement. They perceive loss of self-consciousness, control of the situation, focused attention, positive feedback about the quality of their performance and clear ideas about the aims of the activity. They also report being intrinsically motivated, not pursuing external rewards, the enjoyment being provided by the situation or the activity itself (Deci \& Ryan, 1985).

Specific research tools have been developed to analyze the quality of experience. The experience sampling method provides on-line information about its daily fluctuations (Csikszentmihalyi, Larson \& Prescott, 1977; Csikszentmihalyi \& Larson, 1987). The Flow Questionnaire (Csikszentmihalyi, 1975; Delle Fave \& Massimini, 1988) investigates the psychological features of flow and associated activities or situations. Several cross-cultural studies, which gave rise to a data bank comprising about 4,000 subjects, showed the recurrence of optimal experience in its basic features, regardless of gender, age, or cultural context of the participants (Massimini et al., 1996).

Flow can be associated with the most varied activities, provided that they are valid opportunities for action, engagement and high investment in personal skills. Thus, creative and complex activities - be they work, sports, arts, hobbies, or social interactions - are frequently reported as sources of flow, whereas repetitive and simple tasks are seldom quoted.

Optimal experience promotes individual development. To replicate it, a person will search for increasingly complex challenges in the associated activities and will improve his or her skills accordingly. This process has been defined as cultivation; fosters growth of complexity not only in the performance of flow activities but in individual behavior as a whole. The life-long process of psychological selection, centered on the preferential replication of optimal experience and associated activities, results in the individual's life theme (Csikszentmihalyi \& Beattie, 1979). It can be described as a set of activities, social relations, and life goals uniquely cultivated and pursued by each individual. In this perspective, optimal experience represents the basic unit of psychological selection. To replicate it, individuals cultivate related opportunities for action, which become the components of their life theme.

Being rooted in the subjective evaluation of environmental opportunities, psychological selection leads to individual differentiation within the social group, emphasizing the uniqueness of each individual's developmental trend. Like biology and culture, psychological selection operates as an evolution mechanism. In time, it brings changes in behavior, and it takes part in the progressive differentiation of the individual as a living system.

This approach shows interesting connections with the model developed by Edelman 
$(1989,1992)$ in the field of neuroscience. Edelman applies the Darwinian paradigm to brain development, describing it as the result of an unceasing selection process. Cells of the nervous system grow, migrate, and die during ontogenesis on the basis of environmental selective pressures. Synaptic connections among neurons and neuronal groups enhance or decrease their efficiency throughout life according to the adaptiveness of the behavior their activity supports. This model is extremely close to the psychological selection paradigm. Both perspectives describe individual behavior as strongly influenced by environmental forces, which are independent of genetic information. Both models emphasize individual variation, thus underlining the uniqueness of each nervous system and of each participant in his or her interaction with the environment. Both maintain the role of contextual pressures in promoting the differential reproduction of behavioral traits on the basis of their adaptive features.

In our perspective, however, adaptation does not have only a biological meaning. It also has to be described in cultural terms. In order to fit in their social context, individuals have to reproduce culturally adaptive behaviors. Moreover, individuals are autonomous entities, who actively select environmental information. Their behavior is not aimed simply at bio-cultural adaptation. They build their personalized life project, pursuing differentiation and meanings, as researchers such as Maslow (1968) and Frankl (1978) have pointed out. In our perspective, individuals are the sole authors of their developmental trend, built on the preferential reproduction of those memes that are related to Optimal Experiences.

As in biology and culture, development at the psychological level means growing complexity, (i.e., internal order and integration of the living system). For humans, it can be translated into the harmonization of the individual life theme and cultural opportunities for action. Moreover, given the interdependence of individuals and culture, the growth of complexity involves constructive information exchange with the environment. In order to foster authentic development, psychological selection has to promote a creative and satisfied individual, who is integrated in the cultural environment and committed to the replication of its basic social values.

However, the outcomes of the process depend on the type of activities a person associates with flow, and on the features of his or her life theme. Social contexts do not always provide meaningful opportunities for action, self-expression, and individual growth. On the one hand, modernization and technological development bring about enormous advantages in terms of biological survival, daily life comforts, and the amount of time available for education and leisure; but on the other hand, they bring excessive automation, constraints on work creativity and personal initiative, and a high investment of attention in the use and consumption of artifacts. The gradual loss of traditional know-how and skills implies an increasing dependence of individuals on ready-made solutions to meet daily needs. Thus, during their leisure time people more and more look for challenging and complex activities, such as handicraft, arts, creative writing, adventure travels with limited equipment and facilities, and high-risk sport performances.

The data we gathered with the Flow Questionnaire are consistent with these considerations. For example, few blue- and white-collar workers quote work as a source of Optimal Experience: more associate flow with socialization and leisure activities. These, especially for urbanized samples, are very often represented by traditional skills, such as gardening, knitting, do-it-yourself projects. Conversely, artisans, farmers, teachers, social workers, and professionals frequently report their complex and challenging work activity as a source of flow, also underlining its positive impact on the quality of life (Delle Fave \& Massimini, 1988, 1991). 
As we have previously stated, one of the basic features of flow experience is the participant's engagement in the task at hand (Delle Fave \& Bassi, 1998), in terms of high levels of concentration, alertness, active participation and perception of the importance of the activity. Engagement can be related to the complexity of the challenge an individual is facing, and it has several implications in the process of personal growth. Any activity that requires engagement also entails the cultivation of individual skills, a process that can become a life-long commitment.

Giacomo Leopardi (1798-1837), a well-known Italian man of letters, devoted his life to writing poems, literary and philosophical essays and treatises. In one of his most famous poems, (1828/1972, p.55) "A Silvia", he defines his daily work "gli studi leggiadri...e le sudate carte," the graceful studies and the hard, laborious papers. In one sentence, he synthetically described the joys and torments of complex, highly challenging activities.

This same dedication has been stated by a group of musicians and music students interviewed by means of the Flow Questionnaire (Massimini \& Delle Fave, 1995). For these participants, music involves daily commitment, hard work, and perseverance - in one word, engagement; $72 \%$ reported studying and playing music as the most important source of optimal experience in their daily life. These findings are consistent with the data coming from people devoted to challenging activities, such as surgeons, mountain farmers, mathematicians, and university students. These individuals very frequently associated flow experience with their engaging work or study tasks.

Flow is actively pursued by individuals, but it can also be considered a conquest. It arises out of the constant engagement in skill cultivation; it is not an easy and automatic state, which is one of the reasons why neither repetitive and executive jobs nor passive leisure entertainment, such as watching TV (Delle Fave \& Massimini, 1994; Kubey \& Csikszentmihalyi, 1990), are included as flow-inducing situations.

Nevertheless, some studies conducted with the Flow Questionnaire allowed us to detect the phenomenon of mimetic flow. Some activities can be perceived as sources of optimal experience, they can be actively cultivated but eventually turn out to be poor in complexity potential, which is an essential features of authentic flow activities and a prerequisite for individual development. Moreover, such activities do not foster the participant's constructive integration in the culture. This is true, for example, of drug addiction (Delle Fave, 1996b). Individuals report a flowlike experience in the first period of drug intake. However, the experience is chemically induced, thus artificial. The individual is passive, disengaged from reality, increasingly dependent on drugs and unable to pursue other challenges, and physically weak and marginalized from the social context. Thus, apparent psychological well-being turns out to have a negative effect on bio-cultural fitness and individual development. The same can be said for antisocial activities, such as stealing, which have sometimes been quoted as sources of flow within specific samples. Challenge, engagement, and focus of attention are there; individuals also underline the enjoyment in performing the activity itself, regardless of material rewards. But again, this behavior causes marginalization instead of individual's integration in the cultural context.

\section{Psychological Selection and Individual Development: Some Applications}

Flow experience and psychological selection can be used as the two basic constructs to build a model of optimal psychological functioning and behavioral development. The cultivation of complex opportunities for action fosters personal growth as well as individual active integration in the cultural context. This model can be used in social and psychological 
intervention programs.

Adolescents. Young people are exposed to various sources of mimetic flow in the modernized urban settings of most countries. The intake of psychoactive substances, and the misuse and abuse of technological artifacts such as computers, cars, and weapons are only some examples of apparently complex activities teenagers are attracted to. In most cases, there is a misinterpretation of risk behavior as challenging behavior. No connections with individual development and integration in the social context can be found in such practices.

On the contrary, school and learning activities are often described as low-challenging situations. Many Western countries are facing problems such as students' poor performance and drop-out from high schools. However, building an individual as an adult member of a social group entails an enormous amount of cultural information that children and adolescents are expected to learn from family and school. Several studies have dealt with the structure of educational systems and the quality of experience associated with learning (Csikszentmihalyi, 1982; Csikszentmihalyi, Rathunde, \& Whalen, 1993). In Western countries studying is a mandatory activity for adolescents; however, the contents and the way they are taught are sometimes unfit to capture the attention of the students. Nevertheless, learning can be a very rich source of engagement, personal satisfaction, and meaningful information (Delle Fave \& Bassi, 1998). Its effectiveness as a source of optimal experience can facilitate the acquisition of new knowledge and the active participation of the individual in the process of cultural selection. In our opinion, this is one of the most important issues to deal with in order to enable schools to effectively act as an arena for life skills training and individual development.

For similar reasons, adolescents should be encouraged to engage in structured leisure activities that offering high challenges, potential skills improvement, and developmental chances in terms of cultural integration.

Disablement. The extreme behavioral flexibility that characterizes humans at the biological level has also been detected at the psychological level in studies concerning the quality of experience of disabled persons. In the case of congenital or early infancy deficits, the behavioral constraints do not present obstacles to the process of active psychological selection. Persons born blind reported flow experiences and the building of complex life challenges that enable them to effectively take part in the process of memes' replication, transmission and creative modification (Delle Fave \& Maletto, 1992; Negri, Massimini, \& Delle Fave, 1992). As for handicaps that occur later in life, studies have been conducted on persons who became blind, paraplegic or tetraplegic after athletic, work, or road accidents (Delle Fave, 1996a). The results again emphasize the flexibility of human behavior. After a major trauma that imposes dramatic changes in the daily life and in the access to environmental opportunities for action, individuals can develop a strategy defined as transformation of flow. Where possible, they keep cultivating former flow activities. Otherwise, as often happens, they manage to identify new and unexpected sources of concentration and involvement, sometimes in areas very different from their previous interests.

These results fit very well in the framework of bio-cultural evolution and psychological selection. Behavioral flexibility emerges as a crucial feature for adaptation in the continuously changing environment, be it the ecological niche or the cultural context. At the psychological level, this flexibility enables the individual to pursue developmental goals despite biological constraints. Rehabilitation programs should maximize these individual resources.

Psychopathology. The framework of psychological selection can be fruitfully applied in psychotherapy. The administration of flow-related procedures to persons undergoing psychological treatment proved to be useful for the on-line investigation of the individual 
interaction with the everyday environment (deVries, 1992; Delespaul, 1995). Positive and negative outcomes of this relationship in terms of quality of experience can be detected. Negative states of consciousness, characterized by disruption of attention, disengagement, mood instability and inability to concentrate, which are typical features of several mental disorders, can be related to specific daily situations. Individuals' descriptions of daily opportunities for flow allow the therapist to build a strategy based on individual psychological selection. This can promote a factual developmental process, its aim being not just the recovery from symptoms but the cultivation of meaningful life challenges and the social integration of the individual. The potentials of this approach have been observed both in clinical case studies (Delle Fave \& Massimini, 1992) and in psychiatric interventions developed within international cooperation programs. A therapeutic approach centered on subjective experience and directed toward the cultural reintegration of the individual has been successfully used in the reorganization of two psychiatric structures in Managua, Nicaragua, and in Berbera, Somalia (Inghilleri, 1999). American intervention, supervised by one of the authors, was focused on the rehabilitation of psychotic patients who had been segregated in the Managua psychiatric hospital for decades. A group of them were treated by means of exposure to environmental challenges; specifically, they were recruited for collective work in coffee plantations. This activity, familiar to most of the participants, represented a traditional cultural skill as well as a collaborative group task. The engagement in the work led to a drastic reduction in drugs and a gradual relocation of the participants in their own families and cultural context (Massimini, Terranova, \& Inghilleri, 1985).

Social Maladjustment. Social maladjustment comprises several categories of phenomena, and it involves individuals belonging to all ages. From street children to abandoned elderly persons, from homeless persons to drug addicts, the problem is present under various forms in every society. Maladjusted individuals are exposed to risks at two different levels. First, their potential development through the building of a complex life theme is often seriously limited. Second, marginalization prevents them from taking active part in the process of memes' differential replication and transmission. Data have been collected on the flow experience and life theme among homeless persons, drug addicts, and adolescents living in residential institutions. In all cases, individuals report developmental difficulties both at the personal and cultural levels. The framework of psychological selection and cultural evolution can provide useful guidelines for interventions. The quality of experience has to be evaluated as the key criterion for a successful rehabilitation program. Individuals should be offered opportunities for action according to their personal skills and preferential allocation of psychic resources. However, the ultimate goal of intervention has to be the social reintegration of individuals, by fostering the cultivation of culturally adaptive activities and life goals.

A good application of these theoretical assumptions comes from the work of CWIN (Child Workers in Nepal). This nongovernmental social organization, located in Kathmandu, is involved in socialization and rehabilitation programs for children exposed to labor exploitation, street life, and social and psychological risk factors (CWIN, 1995; Sattaur, 1993). CWIN strategy effectively fosters individual and cultural development, as we could see in recent visits.

Street and labor-bonded children are hosted for some months in CWIN centers. In the meantime contacts are established with their parents to facilitate family reunion and their reintegration in the original social context. Attention is given primarily to promote adjustment to the social context and acquisition of social values: the awareness of child and human rights, and the importance of education, health care, and social equity. Thanks to this new cultural equipment, CWIN children can behave as the core active agents of meaningful cultural changes. 
Rehabilitation programs are individualized and focused on psychological selection and life theme. Children are encouraged to express their life expectations and to follow their intrinsic motivation in cultivating the activities offered in the centers. These activities represent culturespecific opportunities for action, such as traditional skill training, religious practices, meditation, arts, and handicraft. Far too often international intervention programs in developing countries are unrelated to the local culture, being built on Western standards instead. Unfortunately, this stillcommon practice arbitrarily introduces radically unconnected memes in a structured social system. Thus, these memes have few, if any, chances of integration with the local ones, or they can even disrupt the cultural evolution process.

CWIN regularly organizes village-centered advocacy programs on children's issues; to be effective and longlasting, any cultural change requires the commitment of all members of the society. Moreover, it should not undermine the system's stability in the short run, but foster the growth of culture complexity in the long run. The abolition of child labor and street life is not expected to be suddenly realized. Biological speciation is a slow, gradual, time consuming process, eventually giving rise to well-adapted organisms. The same principle can be applied to cultural evolution, and it is one of the pillars of CWIN's careful, exemplary intervention .

Bicultural integration. Cultures often meet in violent ways through wars, land disputes, and religious and ethnic conflicts. Sadly, human history is full of such events, which can result in the imposition of memes by the victors on the vanquished. In other cases, especially in recent times, migration forces individuals to adapt to cultural contexts that are often remarkably different from their original ones. The various outcomes of prolonged exposure to a cultural system other than one's own have been extensively studied in cross-cultural psychology (Berry, Poortinga, Segall, \& Dasen, 1992; LaFromboise, Coleman, \& Gerton, 1993). The key role of psychological selection in coping with the acculturation process arises from data collected by means of Flow Questionnaires in Arizona among Navajos and in Thailand. The two populations are examples of a successful bicultural strategy, leading to the balanced integration of traditional culture with strong modernizing Western influences. Both groups developed specific strategies in pursuing this goal, in line with their culture history (see Inghilleri \& Delle Fave, 1996; Delle Fave \& Inghilleri, 1996). From the perspective of psychological selection, we expect that any society exposed to rapid modernization has to promote the bicultural development of its members as individuals in order to successfully evolve in time. Navajo and Thai participants reported both traditional and modernized activities as sources of optimal experience. The activities ranged from work to leisure, and from social and family interactions to religious practices; they were meaningful components of life theme. The participants were able to achieve a complex integration of memes stemming from two cultural pools at the psychological level, that is, in the daily selection of environmental information.

Unfortunately, not every contact between cultures provides such encouraging outcomes. When traditional societies meet cultures more powerful at the technological and economical level, the most frequent result is assimilation, which involves wild modernization and the loss of entire pools of original knowledge. On the other hand, any effort to rely solely on ancient tradition would ultimately lead to culture seclusion and the risk of extinction in today's era of globalization. Bicultural selection turns out to be the most adaptive strategy, especially when it is grounded in individual daily behavior, in that it allows the individuals' integration in a changing environment. Moreover, this strategy promotes the growth in complexity of the original culture, thanks to the introduction of new memes actively selected and transmitted together with the traditional ones by the individuals. 


\section{Psychological Selection and Biocultural Evolution}

After this excursus through the selective processes shaping human behavior, we would like to make some final remarks.

The individual is the very center of cultural change, as an autonomous agent of memes' differential replication and transmission. Moreover, each human being actively contributes to the building of culture, not just within his or her own limited context but within the whole human environment. This process is particularly clear nowadays when social systems continuously interact and exchange information throughout the planet. As we have previously discussed, the subjective perception of a positive, complex, and intrinsically rewarding state of consciousness, namely flow, fosters the reproduction and transmission of the associated cultural instructions. Flow requires engagement. It is based on involvement in the activity for the sake of the experience and not of extrinsic rewards; it promotes the individual's development and cultural integration.

It is hard to believe that such a complex state of consciousness can be associated with harmful and deviant behavior. Nevertheless, there are mimetic cases that can be misinterpreted as optimal experience and that are too often exploited by charismatic leaders and totalitarian ideologies to support deviance, culture clash, and imposition of power. Moreover, today's leading cultures are centered mainly on extrinsic reward: Modernization, accumulation and consumption of artifacts, and emphasis on economic and material goals are the most striking and recurring features of social systems. The impact of artifacts on natural environment has created serious problems to the biological survival of our species and of the living systems on earth, thus posting a crucial need for social awareness and intervention programs.

Yet, we have evidence that people do not associate flow with money, power, or interpersonal conflict. Flow sheds light on the most constructive, cooperative, creative, and complex aspects of human beings. The constitutions of most societies include citizens' rights, protection and education of children, freedom of faith and expression, and gender and social equality among their basic cultural values. There is a growing effort in the world to build democratic systems, which apparently contrast both the biological tendency to social hierarchy and the inter-cultural conflict among memes (Somit \& Peterson, 1996).

Moreover, human history is interspersed with striking examples of complexity and individual development in people, such as Albert Schweitzer, Mahatma Gandhi, Martin Luther King, Jr., and Mother Teresa. Their lives show a distinctive pattern of selective meme replication, aimed to foster intercultural integration and cooperation beyond cultural selfish reproduction and competition. How can we classify these individuals? Are they inspiring yet isolated exceptions of people who confirm the rule of meme competition in cultural systems? As opponents of cultural conflicts, are they only unaware supporters of species' biological fitness?

What about Aung San Suu Kyi in Burma, Ken Saro-Wiwa in Nigeria, and the hundreds of thousands of political prisoners and persecuted people who risk their life in many countries for the sake of people's freedom and of human rights? Are they only edifying, unmatchable examples, or can they become effective models for common people's behavior and authentic development? How can we finally categorize the countless nurses, teachers, physicians, and religious and social workers who daily and silently devote their life for the sake of mankind?

All of these examples, from the very famous to the anonymous ones, show that individuals can build a life theme centered not only on personal and culture-specific challenges and goals, but also on concerns for other human beings, regardless of their biological and cultural inheritance. Common people involved in socially relevant occupations have witnessed that this concern is a very strong source of optimal experience in their daily life. Thanks to the 
great complexity of the issues and the skills required to deal with them, an individual can choose to devote a conspicuous amount of his or her psychic resources to cultivating the related activities.

We do not mean that life themes focused on other jobs, challenges, or goals are less valuable or meaningful. Instead, we would like to emphasize that every human activity can be performed either from a strictly individual perspective or from a broader one. This extended world outlook should not be confined to personal biological and cultural fitness, but should include mankind as a global living system, whose elements share the same ecological niche and resources, the same biological structure and needs, and the same potentials for growth and development.

In order to be effective the process has to occur in each cultural context - although fragmentation and meme competition seems paradoxically increasing today - in spite of, or because of, closer cultural relationships. Globalization is becoming a more and more concrete reality, but it is based on the Westernization of knowledge and on a system of economical relationships that emphasizes and promotes inequality (Sen, 1992; Chossudovsy, 1997). In these terms, the aim is not to support the development of mankind. Any cultural change, in order to be defined as positive, has to enhance the real complexity of a culture, which entails the improvement of integration among the various components of the culture itself, considered as a dynamic living system. Moreover, the change has to ensure a fruitful exchange with the environment: cooperation and reciprocity between social systems, rather than conflicts, foster cultural evolution in its constructive meaning.

There are still many obstacles to this goal, but there have been several accomplishments up to now. The great world religions are involved in building an ecumenical perspective, one of the most remarkable achievements in this century if we consider that the most relevant values for cultural and individual development are shared by different religious systems. Apart from the extreme positions of integralism, all religions promote the development of the cooperative and altruistic components of human beings (Massimini \& Delle Fave, 1991).

What lesson can be drawn from the evolutionary history of humans, at the three levels of biology, culture, and psychology? It has often been stated that humans do not learn anything from their past. This should mean that cultural evolution, like biological evolution, is blind, and centered on meme selection and transmission only from the perspective of cultural fitness (i.e., the power of meme reproduction). But the specific pattern of brain (and mind) development has made humans self-aware beings. Individuals can reflect upon their actions, make plans for the future, remember (and learn) from past experiences. They are the ultimate creators of culture. They have the power to direct memes' selection from their subjective perspective, pursuing the replication of positive and complex experiences. They look for meaningful life themes, which are not restricted to simple survival or passive acceptance of social norms, regardless of their absolute value.

In order to bequeath a constructive inheritance to the next generations, human beings should be encouraged to invest their limited, and thus precious, psychic resources in opportunities for action which represent real sources of development, not only for the individual, but for the natural and cultural environment (ultimately made of other living beings, be they humans or not). We hope that we have succeeded in exemplifying some of the potential ways to pursue this goal in the previous pages. The present historical period is replete with ethnic conflicts, culture clashes and maladaptive outcomes of wild artifacts' reproduction. Nonetheless, there is a growing awareness of the intrinsic value of diversity and cooperation, at the individual as well as at the social level. These absolute human values should be spread through formal 
education and media, and by means of each individual's assumption of personal responsibility toward the future of the surrounding world. And in this phase of human history, 'world' is not a metaphor to indicate environment. It exactly refers to the world. 


\section{REFERENCES}

Alexander, R. D. (1987). The biology of moral systems. New York: Aldine de Gruyter. Brooks/Cole.

Altman, I., Chemers, M.M. (1980). Culture and Environment. Monterey, California:

Barkow, J.H., Cosmides, L., Tooby, J, The Adapted Mind: Evolutionary Psychology and the Generation of Culture, New York: Oxford University Press.

Berry, J.W., Poortinga, Y.H., Segall, M.H., Dasen, P.R. (1992). Cross-cultural Psychology: Research and Applications. Cambridge: Cambridge University Press.

Boyd, R., Richerson, P.J. (1985). Culture and the Evolutionary Process. Chicago: Chicago University Press.

Brown, L., Flavin C., French, H. (1998). State of the World 1998. Washington: Worldwatch Institute.

Buss, D. (1989). Sex differences in human mate preferences: evolutionary hypotheses tested in 37 cultures. Behavioral and Brain Sciences, 12, 1-49.

Calegari, P., Massimini, F. (1976). Introduzione alla teoria del valori umani. Milano: ISEDI.

Calegari, P., Massimini, F. (1978). Psicologia dell'artefatto normativo sociale. Milano: Franco Angeli.

Chossudovsky, M. (1997). The globalization of poverty: Impact of IMF and World Bank reforms. Third World Network.

Cloak, F.T. (1975). Is a cultural ethology possible? Human Ecology, 3, 161-182.

Crook, J. H. (1980). The evolution of human consciousness. Oxford: Oxford Univ. Press.

Csikszentmihalyi, M. (1975) Beyond Boredom and Anxiety, San Francisco: Jossey Bass.

Csikszentmihalyi, M. (1978) Attention and the holistic approach to behavior. In Pope K.S. and Singer J.L. (Eds.), The Stream of Consciousness, 335-358, New York: Plenum.

Csikszentmihalyi, M. (1982). Intrinsic motivation and effective teaching: a Flow analysis, in J. Bess (Ed.) Motivating professors to teach effectively, 15-26. San Francisco: Jossey Bass.

Csikszentmihalyi, M., Beattie, O. (1979). Life Themes: a theoretical and empirical exploration of their origins and effects. Journal of Humanistic Psychology, 19, 677-693.

Csikszentmihalyi, M., Csikszentmihalyi, I. (Eds.) (1988) Optimal Experience. Psychological studies of Flow in Consciousness, New York: Cambridge University Press.

Csikszentmihalyi, M., Larson, R.W. (1987). Validity and reliability of the Experience Sampling Method. Journal of Nervous and Mental Disease, 175, 526-536.

Csikszentmihalyi, Larson, \& Prescott (1977). The ecology of adolescent activity and experience. Journal of Youth and Adolescence, 6, 281-294.

Csikszentmihalyi, M., Massimini, F. (1985). On the psychological selection of biocultural information. New Ideas in Psychology, 3, 115-138.

Csikszentmihalyi, M., Rathunde, K., Whalen, S. (1993). Talented Teenagers, New York: Cambridge University Press.

CWIN (1995). Voice of child workers, 25. Kathmandu: Indreni Offset Press.

Dawkins, R. (1976). The selfish gene. Oxford: Oxford University Press.

Deci, E.L., Ryan, R.M. (1985). Intrinsic motivation and self-determination in human behavior. New York: Plenum Press.

Delespaul, P.A.E.G. (1995). Assessing schizophrenia in daily life. Maastricht: UPM.

Delle Fave, A. (1996a). Tossicodipendenza e qualità dell'esperienza: un fenomeno di mimetismo, in Massimini F., Inghilleri P., Delle Fave A., (a cura di) La Selezione Psicologica Umana, Milano: Coop.Libraria IULM, 635-652. 
Delle Fave A., (1996b). "Il processo di 'trasformazione di Flow' in un campione di soggetti medullolesi", in Massimini F., Inghilleri P., Delle Fave A., (a cura di) La Selezione Psicologica Umana, Milano: Coop.Libraria IULM, 615-634.

Delle Fave, A., Bassi, M. (1998). Optimal experience and apathy: the meaning of experience fluctuation in adolescents. Paper presented at the VI Biennial EARA Conference, Budapest, June 3-7.

Delle Fave A., Inghilleri P. (1996). "Complessità e coltivazione dell'Esperienza Ottimale nell'eredità culturale thailandese", in Massimini F., Inghilleri P., Delle Fave A., (Eds.) La Selezione Psicologica Umana, Milano: Cooperativa Libraria IULM, 525-540.

Delle Fave A., C.Maletto (1992). "Processi di attenzione e qualità dell'esperienza soggettiva" in Galati D. (Ed.) La Psicologia dei Non Vedenti, 321-353. Milano: Franco Angeli.

Delle Fave A., Massimini F. (1988). "Modernization and the Changing Contexts of Flow in Work and Leisure", in Csikszentmihalyi M., Csikszentmihalyi I. (Eds.): Optimal Experience. Psychological Studies of Flow in Consciousness, 193-213. New York: Cambridge University Press.

Delle Fave, A., Massimini, F. (1991). Modernization and the quality of daily experience in a Southern Italy village, In N. Bleichrodt, P.J.D. Drenth (Eds.) Contemporary Issues in Cross-Cultural Psychology, 110-119. Amsterdam: Swets \& Zeitlinger B.V.

Delle Fave, A., Massimini, F. (1992). Experience Sampling Method and the Measuring of Clinical Change: a Case of Anxiety Syndrome. in M.W. deVries (Ed.) The Experience of Psychopathology, 280-289. Cambridge: Cambridge University Press.

Delle Fave A., Massimini F. (1994). "Frequenza della fruizione televisiva quotidiana e qualità dell'esperienza", Ikon, 28, 11-40.

DeVries, M.W. (Ed.) (1992). The Experience of Psychopathology. Cambridge: Cambridge University Press.

Durham, W.H. (1982). Interactions of genetic and cultural evolution: models and examples. Human Ecology, 10, 289-323.

Durham, W.H. (1991). Coevolution. Genes, culture and human diversity. Stanford, CA: Stanford University Press.

Edelman, G. M. (1989). The remembered present: a biological theory of consciousness. New York: Basic Books.

Edelman, G. M. (1992). Bright air, brilliant fire: on the matter of the mind. New York: Basic Books.

Eisler, R. (1987). The chalice and the blade. San Francisco: Harper and Row.

Flinn, M.V. (1997). Culture and the evolution of social learning. Evolution and Human Behavior, 18, 23-67.

Foley, R.A. (1992). Evolutionary ecology of fossil hominids. In Smith, E.A., Winterhalder, B. (Eds.) Evolutionary Ecology and Human Behavior, 131-164. Hawthorne, NY: Aldine de Gruyter.

Frankl, V.E. (1978). The Unheard Cry for Meaning. New York: Simon and Schuster.

Gimbutas, M. (1991). The civilization of the Goddess. San Francisco: Harper.

Grinde, B. (1996). Darwinian happiness: biological advice on the quality of life. Journal of Social and Evolutionary Systems, 19, 249-260.

Hodge, G.M. (Ed.) (1979). Four Winds. Poems from Indian Rituals. Revised Edition. Santa Fe, New Mexico: The Sunstone Press.

Inghilleri, P. (1999). From subjective experience to cultural change. New York: Cambridge University Press. 
Inghilleri P., Delle Fave A. (1996). "Competizione di Flow: la selezione biculturale dei Navajo", in Massimini F., Inghilleri P., Delle Fave A., (Eds.) La Selezione Psicologica Umana, Milano: Cooperativa Libraria IULM, 505-524.

Jung, C.G. (1972). Ueber die Entwicklung der Persoenlichkeit. Olten: Walter-Verlag.

Kaplan, H., Hill, K. (1992). The evolutionary ecology of food acquisition. In E.A. Smith, B. Winterhalder (Eds.) Evolutionary Ecology, 167-201., Hawthorne, NY: Aldine-de Gruyter.

Khalil, E.L., Boulding, K.E. (Eds.) (1996). Evolution, order and complexity. London: Routledge.

Kim, U., Berry, J.W. (1993). Indigenous Psychologies. Newbury Park, CA: Sage

Kubey R., Csikszentmihalyi, M. (1990) Television and the quality of life, Hillsdale, New Jersey: Erlbaum.

LaFromboise, T., Coleman, H. L. K., Gerton, J. (1993). Psychological impact of biculturalism: evidence and theory. Psychological Bulletin, 114, 395-412.

Leopardi, G. Tutte le opere.Voll.1-4. Binni, W. (Ed) (1989): Canti, operette morali e scritti minori Vol.3. Firenze: Sansoni.

Maslow, A. (1968). Toward a Psychology of Being, 2nd Ed.. Princeton: Van Nostrand.

Massimini, F. (1982). Individuo, cultura, ambiente: i Papua Kapauku della Nuova Guinea Occidentale. Ricerche di Psicologia. 22-23, 27-154.

Massimini, F., Calegari, P. (1979). Il Contesto Normativo Sociale. Milano: Angeli.

Massimini, F., Csikszentmihalyi M., Carli, M. (1987). Optimal experience: a tool for psychiatric rehabilitation. Journal of Nervous and Mental Disease, 175, 545-549.

Massimini, F., Delle Fave, A. (1991). Religion and cultural evolution. Zygon, 26, 27-47.

Massimini, F., Delle Fave, A. (1995). Qualità dell'esperienza e coltivazione di attività musicali. Comunicazioni Scientifiche di Psicologia Generale, 14, 157-181.

Massimini, F., Inghilleri, P., Delle Fave, A. (Eds.) (1996). La Selezione Psicologica Umana, Milano: Cooperativa Libraria IULM.

Massimini, F., Terranova, R., Inghilleri, P. (1985). Cultural model and rehabilitation,. Plan for varied forms of psychopathology. Analytic Psychotherapy and Psychopathology, 2, 5969.

Maturana, H.R. (1975). Autopoietic systems: a Characterization of the Living Organization. Urbana: University of Illinois.

Miller, J.G. (1970). Living Systems. New York: McGraw-Hill.

Monod, J. (1970). Le Hazard et la Necéssité. Trad.it. Il Caso e la Necessità. Milano: Mondadori.

Negri, P., Massimini, F., Delle Fave, A. (1992). "Tema di vita e strategie adattative", in Galati D. (Ed.) La Psicologia dei Non Vedenti, 355-380. Milano: Franco Angeli.

O’Neill, P., Petrinovich, L. (1998). A preliminary cross-cultural study of moral intuitions. Evolution and Human Behavior, 19, 349-367.

Pocklington, R., Best, M. L. (1997). Cultural evolution an units of selection in replicating text. Journal of Theoretical Biology, 188, 79-87.

Prigogine, I., Stengers, I. (1984). Order Out of Chaos. New York: Bantam.

Richerson, P.J., Boyd, R. (1978). A dual inheritance model of human evolutionary process: basic postulates and a simple model I. Journal of Social and Biological Structures, 1, 127-154.

Rokeach, M. (1974). The nature of human values. New York: Free Press.

Ruyle, E.E. (1973). Genetic and cultural pools: some suggestions for a unified theory of biocultural evolution. Human Ecology, 1, 201-215. 
Sattaur, O. (1993). Child labour in Nepal. Kathmandu: CWIN.

Sen, A. (1992). Inequality reexamined. Oxford: Oxford University Press.

Segall, M.H., Lonner, W.J., Berry, J.W. (1998). Cross-cultural psychology as a scholarly discipline. American Psychologist, 53, 1101-1110.

Somit, A., Peterson, S. A. (1996). Indoctrinability as an evolutionary precondition for democracy. Journal of social and Evolutionary Systems, 19, 41-54.

Stevens, A., Price, J. (1996). Evolutionary Psychiatry. London: Routledge.

Stigler, J.W., Shweder, R.A., Herdt, G. (1990). Cultural psychology. New York: Cambridge university Press.

Symons, D. (1990). Adaptiveness and adaptation. Ethology and Sociobiology, 11, 427444.

Tomasello, M., Kruger, A.C., Ratner, H.H. (1993). Cultural learning. Behavioral and Brain Sciences, 16, 495-552.

Trivers, R.L. (1972). Parental investment and sexual selection. In B. Campbell (Ed.) Sexual selection and the descent of man 1871-1971, 136-179, Chicago: Aldine.

Varela, F., Thompson, E., Rosch, E. (1991). The Embodied Mind. Cambridge, MA: MIT Press.

Wilson, E.O. (1976). Sociobiology.: the new synthesis. Harvard Mass.: Bellknap. 